\title{
Soluble mesothelin related peptides (SMRP) and osteopontin as protein biomarkers for malignant mesothelioma: analytical validation of ELISA based assays and characterization at mRNA and protein levels
}

\author{
Alex J. Rai ${ }^{1-3, *}$, Raja M. Flores ${ }^{4}$, Anu Mathew ${ }^{2}$, Rita \\ Gonzalez-Espinoza ${ }^{2}$, Matthew Bott $^{3}$, Marc Ladanyi ${ }^{3}$, \\ Valerie Rusch ${ }^{4}$ and Martin Fleisher ${ }^{2}$ \\ ${ }^{1}$ Department of Pathology and Cell Biology, Columbia \\ University Medical Center, New York, NY, USA \\ ${ }^{2}$ Department of Clinical Laboratories, Memorial Sloan- \\ Kettering Cancer Center, New York, NY, USA \\ ${ }^{3}$ Department of Pathology, Memorial Sloan-Kettering \\ Cancer Center, New York, NY, USA \\ ${ }^{4}$ Department of Surgery, Memorial Sloan-Kettering Cancer \\ Center, New York, NY, USA
}

\begin{abstract}
Background: There is a need to identify reliable markers for malignant mesothelioma. Soluble mesothelin related peptides (SMRP) and osteopontin (OPN) have gained interest in recent years for this purpose.

Methods: SMRP (Fujirebio Diagnostics Inc.) and OPN (R\&D Inc.) ELISA methods were evaluated for multiple parameters. Concentrations were measured in blood from patients with mesothelioma, normal healthy volunteers, and patients with other (non-mesothelioma) cancers. In silico analysis was performed using the GeoProfiles database. At the protein level, SMRP and OPN were measured in cell culture supernatants, and values were compared in patients pre- and post-extrapleural pneumonectomy.

Results: The SMRP assay demonstrates intra-assay CVs of $2.3 \%$ and $3 \%$ (at $4.6 \mathrm{nM}$ and $13.7 \mathrm{nM}$, respectively), and inter-assay $\mathrm{CVs}$ of $3.5 \%$ and $3.7 \%$ at the same concentrations. The limit of detection (LOD) is $0.182 \mathrm{nM}$. The OPN assay demonstrates intra-assay CVs of $5.8 \%, 4.1 \%$, and $5.2 \%$ (at $1.9,5.1$, and $11.1 \mathrm{ng} / \mathrm{mL}$, respectively), and inter-assay CVs of $8.5 \%, 8.4 \%$, and $12.1 \%$ at the same concentrations. The LOD is $0.032 \mathrm{ng} / \mathrm{mL}$. Both SMRP and OPN in mesothelioma patients were significantly higher than in patients with other (non-mesothelioma) cancer and in healthy volunteers. The two markers do not appear to correlate with each other and exhibit different tissue expression patterns.
\end{abstract}

*Corresponding author: Alex J. Rai, PhD, DABCC, FACB, Assistant Professor of Pathology, Director, Special Chemistry Laboratory, Chief Scientific Officer, Center for Advanced Laboratory Medicine, Columbia University Medical Center 622 West 168th Street, CHONY 2C-224, New York, NY 10032, USA

Fax: +1-212-305-7553, E-mail: alex.rai@columbia.edu Received February 24, 2009; accepted November 1, 2009
Protein concentrations of these markers are highest in different sets of cell lines. Finally, SMRP but not OPN concentrations were decreased in five of seven consecutive patients after extrapleural pneumonectomy, compared to their respective pre-operative values.

Conclusions: These assays provide reliable and reproducible quantitation of SMRP and OPN proteins. Both are increased in mesothelioma patients compared to non-mesothelioma controls. However, the two analytes do not correlate with each other and show distinct expression profiles and protein expression. Concentrations of SMRP but not OPN are decreased in post-surgical samples. Our results further characterize these markers, establish assay performance characteristics, and lay the groundwork for further studies to measure these markers in blood.

Clin Chem Lab Med 2010;48:271-8.

Keywords: analytical validation; cancer biomarkers; mesothelin; mesothelioma; osteopontin; soluble mesothelin related peptides.

\section{Introduction}

Diffuse malignant pleural mesothelioma is an uncommon and lethal cancer for which there is currently no universally accepted treatment standard (1-4). The incidence of malignant mesothelioma is estimated at 2000-3000 cases annually in the USA (5). In Western Europe alone, a quarter of a million deaths are projected over the next 30 years (6). It is important for thoracic physicians to be knowledgeable about mesothelioma because they are often required to make a diagnosis and recommend treatment.

Diagnosis of mesothelioma can be difficult. It presents with a wide range of morphological characteristics on histology, making it difficult to differentiate from other malignancies (7). Similarities exist between epithelioid mesothelioma and metastatic adenocarcinoma. Immunohistochemistry has been useful in differentiating mesothelioma from adenocarcinoma. Many have found the distinction by identifying calretinin in mesothelioma and carcinoembryonic antigen (CEA) in adenocarcinoma. Other difficulties exist in differentiating sarcomatoid mesothelioma from synovial sarcoma, desmoplastic mesothelioma from pleural fibrosis, and well-differentiated mesothelioma from papillary hyperplasia. No marker has $100 \%$ sensitivity or specificity for the diagnosis of mesothelioma, and commonly a panel of markers, 
such as CEA, tumor-associated glycoprotein 72 [B72.3], Leu-M1, vimentin, thrombomodulin, secretory component, carcinoma antigen-125, and mucin is employed (8). Sometimes the distinction is still not possible and electron microscopy is used to identify the numerous long microvilli present in mesothelioma. A biomarker specific for the diagnosis of mesothelioma would prove very useful for accurate diagnosis.

Malignant pleural mesothelioma is also difficult to evaluate radiologically due to its propensity to infiltrate locally into and along tissue planes. Computed tomography and magnetic resonance imaging have been used to clinically stage disease. Unfortunately, there are major discrepancies when compared to surgical-pathological findings $(9,10)$. There is evidence that the treatment of early stage disease using extrapleural pneumonectomy or pleurectomy/decortication may improve survival (11-14). However, 20\%$30 \%$ of patients undergo exploratory thoracotomy without resection because of the unreliability of current radiological modalities in predicting locally advanced disease (i.e., unresectable disease) (2). Several studies have suggested that FDG PET (position emission tomography) may be useful in the pre-operative staging of this disease $(15,16)$. A better method of determining extent of disease is necessary to improve surgical outcome and minimize the number of patients subjected to exploratory thoracotomy without surgical resection. A biomarker that is a surrogate marker for the extent of disease may help determine initial treatment, response to treatment, and determine recurrence of disease during routine follow-up.

Two markers, mesothelin and osteopontin (OPN), have garnered interest in recent years for monitoring therapy or detecting recurrence of mesothelioma. Mesothelin, encoded by the MSLN gene, is a member of the megakaryocyte potentiating factor (MPF) family and is produced specifically in mesothelium cells. It is believed to play a role in cellular adhesion. MSLN mRNA is translated into a preprotein form which is post-translationally cleaved into two products, MPF and mesothelin (17-19). Three mesothelin transcripts have been reported in the literature: variant 1 encoding MPF (NM_005823), variant 2 encoding mesothelin (NM_ 013404), and variant 3 (AF180951) (20-24). Studies from ovarian and pancreatic cancer cell lines and tissue support the existence of variants 1 and 3 only, with variant 1 being the predominant form (24). The mesothelin portion of this protein is detectable using an ELISA method which targets the soluble mesothelin related peptides (SMRP). Because mesothelioma is a rare disease, this assay has been FDA (Food and Drug Administration) approved for humanitarian use and its intended application is to aid in the monitoring of patients diagnosed with mesothelioma.

The second marker, OPN, is a glycoprotein that is abundantly expressed by several cancers including lung, breast, colorectal, gastric, ovarian, and melanoma (19). It is involved in cell adhesion and has been shown to distinguish mesothelioma patients from individuals that are exposed to asbestos without malignancy (25). There are three isoforms of this protein present in human cells: NM_001040058, NM_000582, and NM_001040060 (26). OPN protein can be detected in the circulation using antibodies that target this protein.

The purpose of this study was to further characterize mesothelin and OPN. We performed an analytical and clinical validation of two ELISA based methods for these markers, established normal reference intervals for our patient population, and characterized the protein concentrations in blood samples from patients with different cancers. We also assessed both molecules at the mRNA level in human tissues and protein concentrations in cell line supernatants. Our results help characterize further both mRNA and proteins for these two markers, establish performance characteristics for these assays, and lay the groundwork for further studies.

\section{Materials and methods}

\section{SMRP ELISA immunoassay}

SMRP ELISA - Mesomark ${ }^{\mathrm{TM}}$ (Fujirebio Diagnostics Inc., Malvern, PA, USA) is a sandwich immunoassay used to quantitate SMRP in human serum. There is a six-point standard curve $(0-32 \mathrm{nM})$ and the assay was performed per the manufacturer's instructions. All samples were measured in duplicate and the mean calculated. Briefly, $10 \mu \mathrm{L}$ of serum samples to be tested are diluted into $1 \mathrm{~mL}$ of calibrator solution. $100 \mu \mathrm{L}$ of calibrators, controls and diluted samples are dispensed into the appropriate well in the coated microtiter plate and then incubated on a shaker for $60 \mathrm{~min}$. The plate is decanted and washed five times with $350 \mu \mathrm{L}$ of wash buffer in each well. Subsequently, $100 \mu \mathrm{L}$ of conjugate (monoclonal antibody specific for MSLN conjugated to horseradish peroxidase) is added and the plate incubated for $60 \mathrm{~min}$. The plate is then washed five times with $350 \mu \mathrm{L}$ of wash buffer in each well. $100 \mu \mathrm{L}$ of substrate solution (tetramethylbenzidine) is added and the plate is incubated in the dark for $15 \mathrm{~min} .1 \%$ hydrochloric acid is added to stop the reaction and the plate is read spectrophotometrically at $450 \mathrm{~nm}$ using a BioTek ELx808 ultra microplate reader (BioTek Instruments Inc., Winooski, VT, USA).

\section{Osteopontin immunoassay}

The Quantikine ${ }^{\circledR}$ OPN immunoassay (R\&D Systems Inc., Minneapolis, MN, USA) is a 4.5-h solid-phase ELISA that employs a sandwich immunoassay to quantitate human OPN in plasma (dilution required). The ELISA was performed per the manufacturer's instructions. All samples are measured in duplicate and the average calculated. Briefly, a standard curve (4-parameter fit) is generated by diluting a stock standard solution $(200 \mathrm{ng} / \mathrm{mL})$ to the following concentrations: $20,10,5,2.5,1.25,0.625,0.312$, and $0 \mathrm{ng} / \mathrm{mL}$. One hundred $\mu \mathrm{L}$ of diluent is added to $50 \mu \mathrm{L}$ of standards, controls, or samples into designated wells of the microtiter plate, and coated with a monoclonal antibody specific to OPN. The plate is incubated at room temperature for $2 \mathrm{~h}$. It is then washed four times with wash buffer and $200 \mu \mathrm{L}$ of conjugate containing anti-OPN polyclonal antibody-horseradish peroxidase conjugate is added to the wells. After a 2-h, room temperature incubation, the plate is decanted and washed four times with $400 \mu \mathrm{L}$ of wash buffer. Finally, $200 \mu \mathrm{L}$ of substrate (tetramethylbenzidine) is added to the wells and the plate is incubated in the dark for $30 \mathrm{~min}$. The reaction is stopped by the 
addition of $50 \mu \mathrm{L}$ of $2 \mathrm{~N}$ sulfuric acid and read at $450 \mathrm{~nm}$ with $\lambda$ correction at $530 \mathrm{~nm}$.

\section{Patient recruitment}

Institutional Review Board approval was obtained at Memorial Sloan-Kettering Cancer Center (MSK; New York, NY) for the collection of serum and heparinized plasma from study patients. Consecutive clinic patients for whom eligibility criteria were met, i.e., mesothelioma diagnosis without previous treatment, were used in this study. For these samples, the age range was 55-70 years, with a median of 64 years. The majority of mesothelioma samples were from patients in stage $2-3$, including those that underwent extrapleural pneumonectomy. The remaining samples were from patients in stage 4. Greater than $90 \%$ of samples had an epitheliod component, i.e., comprised of pure epitheliod and also mixed histology specimens. Less than $10 \%$ of the remaining specimens were from patients with sarcomatoid mesothelioma.

Control samples were obtained from: 1) a pool of volunteer healthy donors without evidence of disease; these donors had an age range from 40 to 59 years, with a median of 54 years, 2) blood samples from patients $(\mathrm{n}=10$ each group) diagnosed with prostate, breast, and ovarian cancer, most with late stage cancer, enrolled in clinical protocols at MSK.

All patients signed informed consent for collection of blood and tissue. A pilot cohort of seven consecutive patients who underwent extrapleural pneumonectomy had mesothelin and OPN concentrations measured before and after surgical resection at designated time intervals, with comparisons performed on 1 week pre-surgical and 6 month post-surgical samples.

\section{Sample collection and processing}

Blood samples were centrifuged and serum/plasma separated within $30 \mathrm{~min}$ of collection. All samples were spun at $1500 \times \mathrm{g}$ for $10 \mathrm{~min}$ to separate cellular components. Serum or plasma were subsequently transferred to cryotubes and stored at $-80^{\circ} \mathrm{C}$, until further analysis.

\section{Analytical parameters and statistical analysis}

The limit of detection (LOD) was determined using 20 replicates of a blank solution and calculated as follows: $\mathrm{LOD}=$ mean $+2 \mathrm{SD}$. Intra-assay precision was determined using 20 replicates of control samples at the appropriate concentrations, and the mean, SD, and CV (\%) calculated. Inter-assay precision was calculated similarly, using four daily runs.

Receiver operating characteristic (ROC) curves were created using MedCalc (MedCalc Software, Mariakerke, Belgium) on a cohort of 201 samples (140 mesothelioma + non-mesothelioma).

For comparison of SMRP and OPN between different sample cohorts, a two-tailed heteroscedastic t-test was performed, with significance set at $p=0.05$. For comparison of pre-surgical and postsurgical samples, a paired, two-tailed Student's t-test was performed, and significance assessed using $\mathrm{p}=0.05$.

\section{Tissue survey mRNA}

This tissue survey was performed in silico using the GEO profiles database (accession number: GDS1096/204885_s_at/MSLN/Homo sapiens for MSLN and GPL96/209875_s_at/Homo sapiens for OPN). Results show expression profiling of 36 types of normal tissue, with each RNA tissue sample pooled from several donors.
For additional experimental details, see reference (27). GAPDH mRNA was used for normalization.

\section{Cell culture samples}

Three mesothelioma cell lines (VAMT, Meso37, and HMeso), three lung cancer cell lines (A549, PC9, and H3255), and two other immortalized cell lines (HeLa cervical adenocarcinoma cells and HEK-293 human embryonal kidney cells) were used in this study. For the lung cancer cell lines, A549 cells have activating mutation in KRAS, PC9 cells have exon 19 deletion in epidermal growth factor receptor (EGFR) and are sensitive to EGFR inhibitors, and H3255 cells have the L858R mutation in EGFR and are sensitive to EGFR inhibitors. All are NSCLC adenocarcinomas. Cell lines were obtained courtesy of Molecular Diagnostics Service (Memorial Hospital of MSK, New York, NY). HeLa cells were grown in DMEM with $10 \%$ fetal calf serum (FCS) and penicillin (100 U/mL) and streptomycin $(100 \mu \mathrm{g} / \mathrm{mL})$. The remaining cell lines were grown in RPMI-1640 with $10 \%$ FCS and penicillin $(100 \mathrm{U} / \mathrm{mL})$ and streptomycin $(100 \mu \mathrm{g} / \mathrm{mL})$. All cells were grown in a humidified incubator at $37^{\circ} \mathrm{C}$ and $5 \% \mathrm{CO}_{2}$.

On day 0 of the study, $1 \times 10^{5}$ cells were plated into $100 \mathrm{~mm} \times 20$ $\mathrm{mm}$ round cell culture dishes in triplicate. One $\mathrm{mL}$ of medium was harvested from each dish at day 3. After harvesting, $1 \mathrm{~mL}$ of fresh medium was returned to the dish to keep the total volume stable. On day 4 , all cells were trypsinized and counted. Cell counts ranged from $2.5 \times 10^{5}$ cells per plate $(\mathrm{H} 3255)$ to $9 \times 10^{6}$ cells per plate (VAMT). All samples were sent for total protein quantitation immediately after collection.

\section{Results}

\section{Analytical validation}

The SMRP assay demonstrated an intra-assay CV of $2.3 \%$ at a mean of $4.6 \mathrm{nM}$, and $3 \%$ at a mean of $13.7 \mathrm{nM}$. The inter-assay CV was $3.5 \%$ and $3.7 \%$ at these same concentrations. The LOD was found to be $0.182 \mathrm{nM}$. For the OPN assay, precision was assessed at three levels and the following results were obtained: $5.8 \%$ at a mean of $1.9 \mathrm{ng} / \mathrm{mL}$, $4.1 \%$ at a mean of $5.5 \mathrm{ng} / \mathrm{mL}$, and $5.2 \%$ at a mean of $11.1 \mathrm{ng} / \mathrm{mL}$. At these same levels, the inter-assay $\mathrm{CV}$ was found to be $8.5 \%, 8.4 \%$, and $12.5 \%$, respectively. The LOD for OPN was $0.032 \mathrm{ng} / \mathrm{mL}$.

\section{Reference interval assessment, ROC curves, and correlation analysis}

We measured SMRP concentrations in 51 healthy volunteers and observed a range up to $0.82 \mathrm{nM}$. SMRP concentrations in blood samples from patients with mesothelioma and nonmesothelioma cancers are shown in Figure 1A. For OPN, we observed a range of $7.5-67.5 \mathrm{ng} / \mathrm{mL}$ in normal individuals. OPN concentrations in mesothelioma and non-mesothelioma patients are shown in Figure 1B. To determine the utility of these two markers in mesothelioma patients and normal volunteer samples, we designed ROC curves for each, shown in Figure $2 \mathrm{~A}$ and $\mathrm{B}$.

Interestingly, although each of the individual assays shows excellent correlation when replicates for the same assay are 

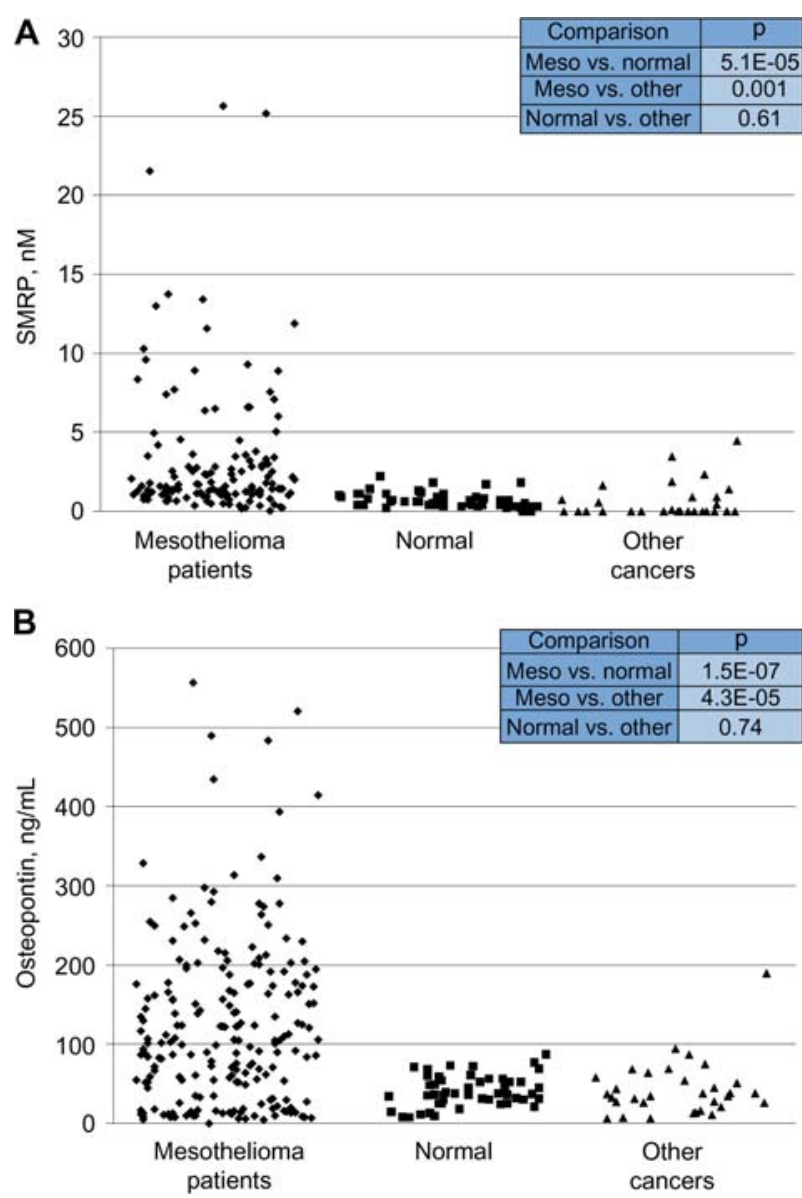

Figure 1 SMRP and OPN concentrations in patients and controls. (A) SMRP concentrations in mesothelioma $(3.24 \pm 4.27, \mathrm{n}=139)$, normal $(0.72 \pm 0.47, \mathrm{n}=51)$, and non-mesothelioma (other cancer) patients $(0.63 \pm 1.12, \mathrm{n}=30)$; (B) OPN concentrations in mesothelioma $(129 \pm 115, \mathrm{n}=205)$, normal $(41 \pm 19, \mathrm{n}=51)$, and non-mesothelioma (other cancer) patients $(43 \pm 35, \mathrm{n}=30)$. $\mathrm{p}$-Values are indicated in inset for each of the comparisons.

compared, the concordance between mesothelin and OPN proteins in these same specimens is poor (Figure 3).

\section{Tissue survey mRNA}

We interrogated the GeoProfiles database for expression levels of mesothelin (MSLN, isoform 1) and OPN (isoform 1) mRNAs in different human tissues. MSLN was expressed highest in fetal lung, lung and trachea, with lower levels in several other tissues (Figure 4A). We also investigated OPN mRNA in the same sample set. OPN mRNA exhibited highest concentrations in kidney, with moderate expression in corpus, fetal brain, pancreas, and placenta (Figure 4B).

\section{Protein concentrations in cell lines}

We also tested corresponding cell line supernatants from eight representative cell lines. We found SMRP protein to be highest in Meso37 and HeLa cell lines and OPN to be highest in A549 and PC9 cell lines (Figure 5).
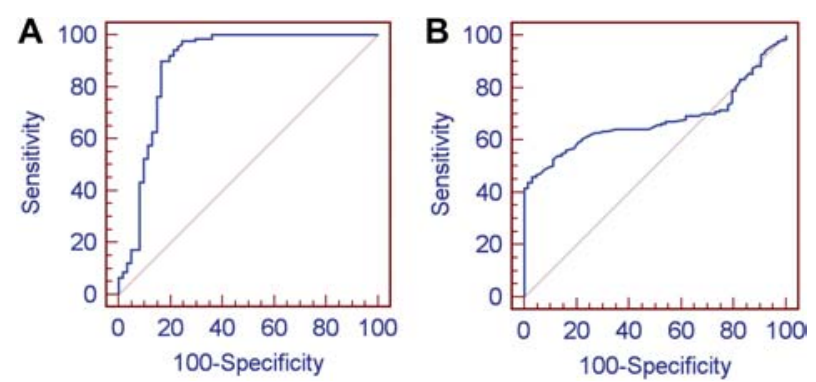

Figure 2 ROC curve analysis.

Empirical ROC curve for separating mesothelioma patients vs. normal volunteers and patients with other cancers using (A) SMRP, and (B) OPN. The AUC (95\% CI) values are: 0.89 (0.83-0.92) for SMRP and $0.68(0.61-0.74)$ for OPN.

\section{Pre-operative vs. post-operative blood concentrations from extrapleural pneumonectomy patients}

We also obtained blood samples from seven consecutive patients with mesothelioma who underwent extrapleural pneumonectomy at Memorial Hospital. We measured blood concentrations of SMRP and OPN from samples obtained from these patients. The concentrations of SMRP decreased in five of seven post-surgical patient samples (Figure 6). For the remaining two patients, SMRP remained unchanged in one patient and increased slightly in the other. OPN did not show any consistent directional change in this small cohort (data not shown).

\section{Discussion}

The treatment of malignant pleural mesothelioma is controversial, but has evolved considerably during the past several decades. However, many areas need further improvement: easier and more accurate methods of pathological diagnosis, improved methods of staging and of selecting patients for surgery, assessment of response to chemotherapeutic and sur-

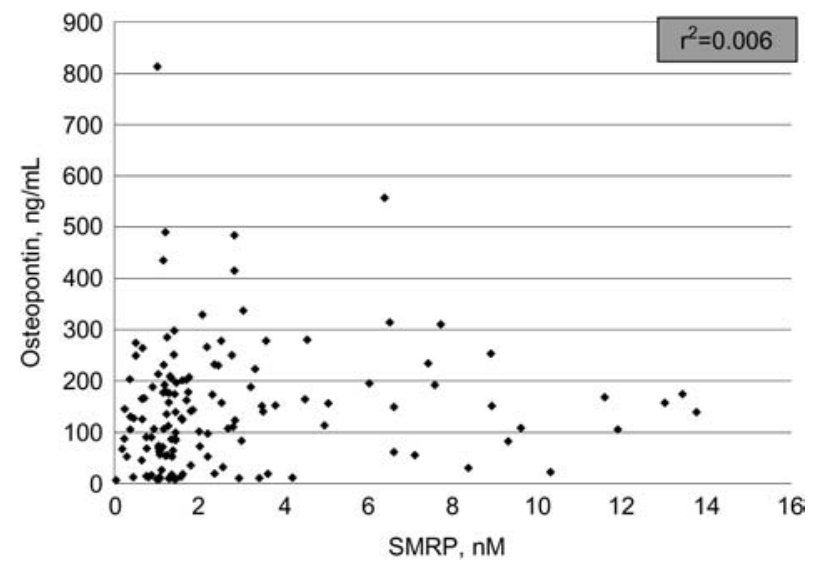

Figure 3 Correlation analysis: osteopontin vs. SMRP. Correlation was performed using 135 samples for which both mesothelin and osteopontin results were available. 

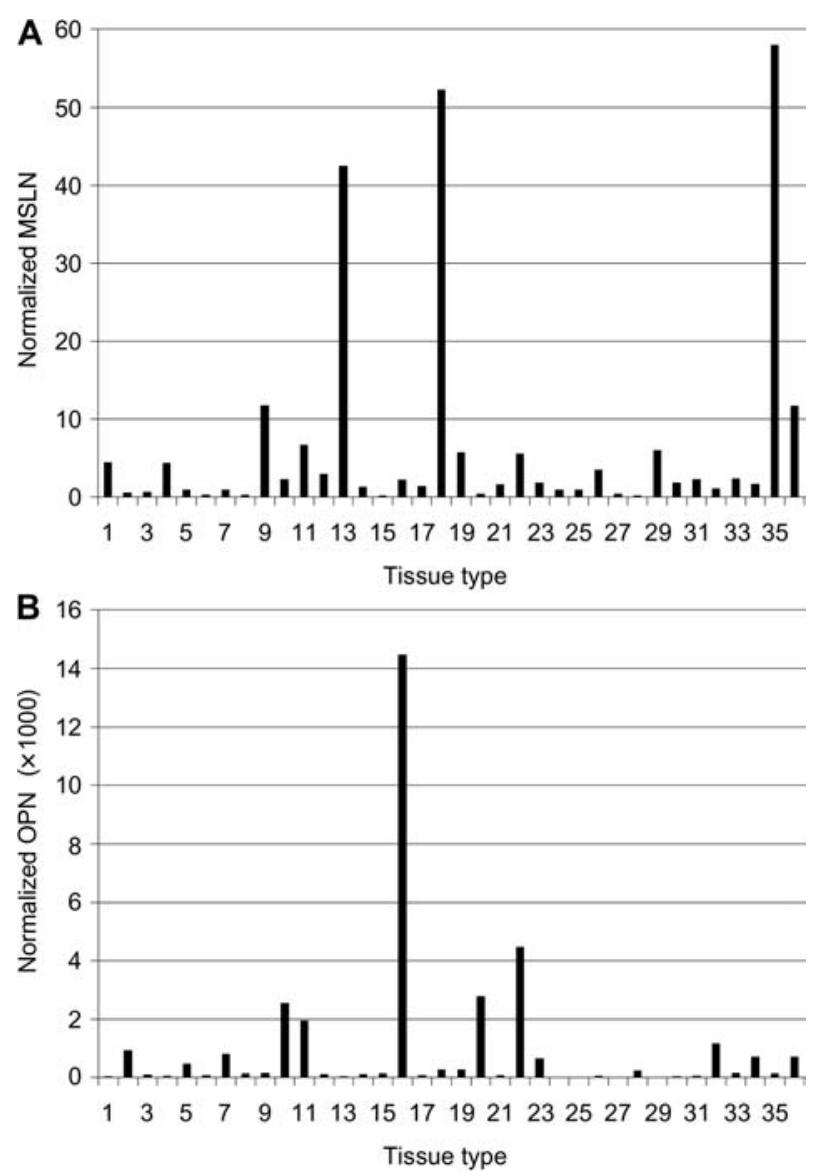

Figure 4 Concentrations of (A) MSLN and (B) OPN mRNAs in different human tissues.

(1) Adrenal gland, (2) amygdala, (3) bladder, (4) bone marrow, (5) brain, (6) breast, (7) caudate nucleus, (8) cerebellum, (9) colon, (10) corpus, (11) fetal brain, (12) fetal liver, (13) fetal lung, (14) heart, (15) hippocampus, (16) kidney, (17) liver, (18) lung, (19) ovary, (20) pancreas, (21) pituitary gland, (22) placenta, (23) prostate, (24) smooth muscle, (25) salivary gland, (26) skin, (27) small intestine, (28) spinal cord, (29) spleen, (30) stomach, (31) testis, (32) thalamus, (33) thymus, (34) thyroid, (35) trachea, (36) uterus. Note that mRNA levels are normalized to GAPDH.

gical treatment, and assessment of disease recurrence in routine follow-up (28-33). Non-invasively obtained biomarkers specific to mesothelioma would improve care for all aspects of disease assessment and treatment $(18,20)$. In this study, we further characterized two markers, mesothelin and OPN, at the mRNA and protein levels, and defined the performance characteristics for ELISA methods for quantitative analysis in cell lines and blood.

Mesothelin is a differentiation antigen previously identified in pleura, peritoneum, and pericaridium (34). In humans, it is encoded by the MSLN gene which produces a protein of $71 \mathrm{kDa}$. This preprotein is the target of certain furin-like proteases that cleave the molecule into two fragments. A 31$\mathrm{kDa}$ amino terminal fragment called MPF is released into the circulation, and a 40-kDa product, mesothelin, remains membrane bound. Three molecular variants of mesothelin

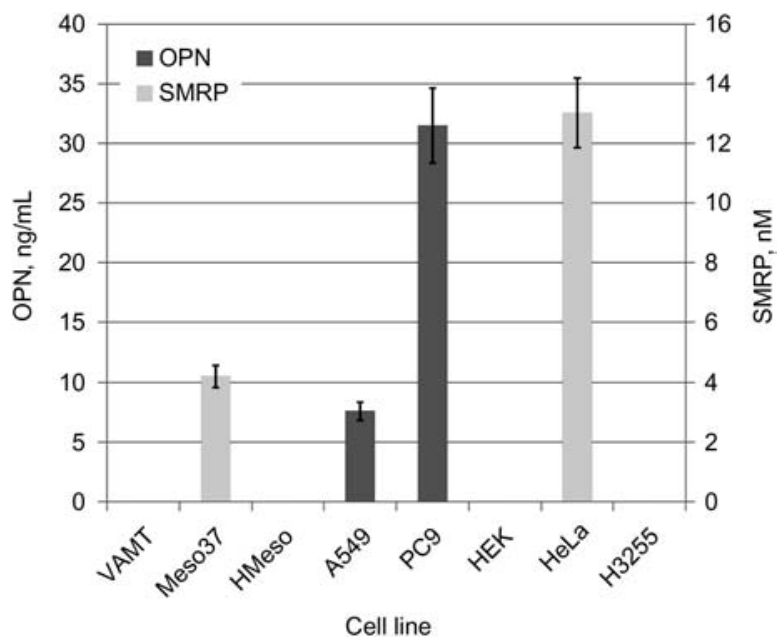

Figure 5 Concentrations of SMRP and osteopontin protein in cell line supernatants.

have been reported in the literature (accession numbers NM_005823.4, NM_013404.3, and AF180951), but only the existence of variants 1 and 3 has been demonstrated in ovarian and pancreatic cell lines and ovarian cancer tissue $(17,34)$.

OPN is a glycoprotein that is overexpressed in many human cancers including lung, breast, colorectal, gastric, ovarian, and melanoma (19). One important role for OPN lies in its ability to distinguish mesothelioma from asbestos exposure without malignancy $(19,25)$. There are three genes encoding isoforms $\mathrm{a}, \mathrm{b}$, and $\mathrm{c}$ of OPN (accession numbers NM_001040058.1, NM_000582.2, and NM_001040060.1) (26).

We validated assays for both SMRP and OPN, and used them for quantitation of the concentrations of their respective proteins in blood samples from patients with and without mesothelioma (Figure 1). Performance characteristics including intra-assay and inter-assay precision, LOD, reference

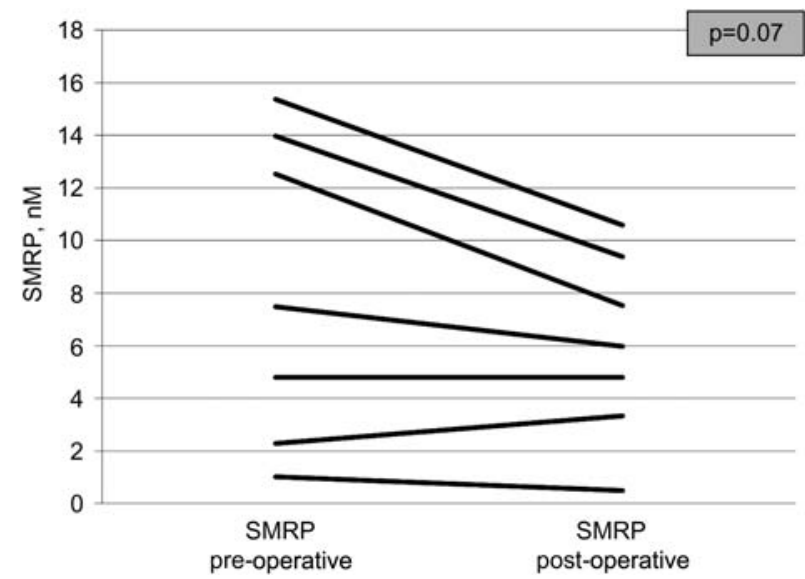

Figure 6 Comparison of SMRP concentrations in pre- and postspecimens from 7 extrapleural pneumonectomy (EPP) surgery patients. 
interval assessment and comparison of concentrations of both proteins in mesothelioma and non-mesothelioma patients were determined. Our data suggest satisfactory performance of these assays in measurement of their respective analytes. They also provide baseline measurements and lay the groundwork for additional studies using blood samples from patients with and without mesothelioma and those undergoing treatment. Our results from LOD and precision studies are in close agreement with those of Beyer et al. (35). In addition, our reference interval data are narrower but consistent with the broader range established in this former study.

SMRP and OPN values do not correlate with each other (Figure 3). This suggests that at a functional level, the proteins are not redundant and thus likely to be involved in distinct pathways. This possibility is further reinforced by the different expression patterns of these two biomarkers. An in silico analysis of MSLN and OPN mRNAs in 36 human tissues was performed using GeoProfiles (http://www.ncbi. nlm.nih.gov/sites/entrez); see Figure 4. MSLN, the gene which encodes mesothelin, and whose protein product is detected by the SMRP assay, shows highest concentrations in fetal lung, lung, and trachea, with lower concentrations in several other tissues. In contrast, the $O P N$ gene is expressed in highest amounts in kidney, with moderate levels in corpus, fetal brain, pancreas and placenta. The distinct expression pattern of these two molecules suggests different functions.

We measured the concentrations of both SMRP and OPN proteins in eight representative cancer cell lines. For SMRP, we observed highest protein concentrations in the supernatants of Meso37 and HeLa, with values below detection for the rest of the cell lines. It is remarkable that only one of the mesothelioma cell lines (Meso37) showed measurable concentrations of this marker. In reviewing microarray expression data obtained from analysis of these three cell lines, we noted that the Meso37 cell line expresses mesothelin mRNA at two orders of magnitude higher than VAMT and HMeso cell lines (data not shown). Thus, it is possible, and consistent with our ELISA results, that Meso37 produces mesothelin protein at concentrations that fall within the dynamic range of our assay and that the other cell lines which contain $100 \times$ less mesothelin mRNA produce values below detectable limits when measured with our assay.

For OPN, we observed highest concentrations of this protein in A549 and PC9 cell lines, with concentrations below the detection limit for the remaining cell lines. Both A549 and PC9 are derived from lung cancer patients. It is interesting that $\mathrm{H} 3255$, which is also a lung cancer derived cell line, does not show measurable concentrations of OPN, particularly since both PC9 and H3255 are sensitive to EGFR inhibitors. At the molecular level, PC9 cells contain EGFR with exon 19 deletion, and H3255 cells contain EGFR with L858R mutation. It is conceivable that such a difference could activate different downstream effector proteins with only PC9 cells activating a signal transduction pathway that results in mesothelin protein production and/or secretion. Interestingly, A549 cells which contain an activating KRAS mutation, activates downstream signaling resulting in mesothelin secretion similar to PC9 cells.

To assess reference intervals, we measured the concentrations of SMRP and OPN in a cohort comprised of normal healthy volunteers, mesothelioma and non-mesothelioma (i.e., other cancer) patients. In 51 normal healthy volunteers, we observed a range of values up to $0.82 \mathrm{nM}$. This measured range is narrower, but falls within the reference interval stated in the product insert and based on the study by Beyer et al., who calculated the 99th percentile of the reference group to be $1.5 \mathrm{nM}$ (35). This discrepancy can be reconciled by the size of our reference group $(n=51)$ which is much smaller than that of theirs $(n=409)$. When we measured samples from mesothelioma patients, they showed a broad range of results with maximum at $26 \mathrm{nM}$. Patients with prostate, breast, and ovarian cancer exhibited values up to $5 \mathrm{nM}$.

OPN concentrations were measured in the same cohort, and are shown in Figure 1B. Similar to SMRP, highest values were observed in mesothelioma patients (maximum of $525 \mathrm{ng} / \mathrm{mL}$ ), lower concentrations in patients with other cancer (maximum of $200 \mathrm{ng} / \mathrm{mL}$ ), and values levels in normal healthy volunteers (maximum of $70 \mathrm{ng} / \mathrm{mL}$ ). Our observed values are somewhat lower than those suggested by the manufacturer $(53-195 \mathrm{ng} / \mathrm{mL})$, but this difference may be reconciled by the small cohort of 51 patients analyzed in our study, or the possibility that our patient population is different from that previously tested.

Finally, we analyzed SMRP and OPN concentrations in a small group of seven consecutive patients undergoing extrapleural pneumonectomy. We observed that SMRP, but not OPN, showed a decrement in five of seven post-surgical samples as compared to paired pre-surgical specimens. Although this result did not achieve statistical significance $(p=0.07)$, it would be of great interest to assess concentrations of this marker at different time points and/or in a larger cohort of paired samples.

In conclusion, our data establish the reliability and reproducibility of two assays to quantitate SMRP and OPN proteins. We assessed reference intervals for both markers and show that the two do not correlate well in our sample set. Tissue expression surveys at the mRNA level show distinct profiles, as do the concentrations of the corresponding proteins in cell line supernatants. Finally, concentrations of SMRP but not OPN, decrease in post-surgical samples after extrapleural pneumonectomy. This is a promising preliminary result and warrants further investigation in a larger cohort.

\section{Conflict of interest statement}

Authors' conflict of interest disclosure: The authors stated that there are no conflicts of interest regarding the publication of this article.

Research funding: None declared. Employment or leadership: None declared.

Honorarium: None declared. 


\section{References}

1. Kindler HL, Belani CP, Herndon JE 2nd, Vogelzang NJ, Suzuki Y, Green MR. Edatrexate (10-ethyl-deaza-aminopterin) (NSC \#626715) with or without leucovorin rescue for malignant mesothelioma. Sequential phase II trials by the cancer and leukemia group B. Cancer 1999;86:1985-91.

2. Kindler HL, Millard F, Herndon JE 2nd, Vogelzang NJ, Suzuki Y, Green MR. Gemcitabine for malignant mesothelioma: a phase II trial by the Cancer and Leukemia Group B. Lung Cancer 2001;31:311-7.

3. Otterson GA, Herndon JE, Watson D, Green MR, Kindler HL. Capecitabine in malignant mesothelioma: a phase II trial by the Cancer and Leukemia Group B (39807). Lung Cancer 2004;44:251-9.

4. Pass HI, Temeck BK, Kranda K, Thomas G, Russo A, Smith $\mathrm{P}$, et al. Phase III randomized trial of surgery with or without intraoperative photodynamic therapy and postoperative immunochemotherapy for malignant pleural mesothelioma. Ann Surg Oncol 1997;4:628-33.

5. Price B, Ware A. Mesothelioma trends in the United States: an update based on surveillance, epidemiology, and end results program data for 1973 through 2003. Am J Epidemiol 2004; 159:107-12.

6. Peto J, Decarli A, La Vecchia C, Levi F, Negri E. The European mesothelioma epidemic. Br J Cancer 1999;79:666-72.

7. Pass HI, Mitchell JB, Johnson DH, Turrisi AT, Minna JD, editors. Lung cancer - principles and practice. New York: Lippincott Williams \& Wilkins, 2000.

8. Brown RW, Clark GM, Tandon AK, Allred DC. Multiple-marker immunohistochemical phenotypes distinguishing malignant pleural mesothelioma from pulmonary adenocarcinoma. Hum Pathol 1993;24:347-54.

9. Heelan RT, Rusch VW, Begg CB, Panicek DM, Caravelli JF, Eisen C. Staging of malignant pleural mesothelioma: comparison of CT and MR imaging Am J Roentgenol 1999;172: 1039-47.

10. Patz EF Jr, Shaffer K, Piwnica-Worms DR, Jochelson M, Sarin M, Sugarbaker DJ, et al. Malignant pleural mesothelioma: value of CT and MR imaging in predicting resectability. Am J Roentgenol 1992;159:961-6.

11. Flores RM, Pass HI, Seshan VE, Dycoco J, Zakowski M, Carbone M, et al. Extrapleural pneumonectomy versus pleurectomy/decortication in the surgical management of malignant pleural mesothelioma: results in 663 patients. J Thorac Cardiovasc Surg 2008;135:620-6, 626.e1-3. Epub 2008 Feb 14.

12. Butchart EG, Ashcroft T, Barnsley WC, Holden MP. Pleuropneumonectomy in the management of diffuse malignant mesothelioma of the pleura: experience with 29 patients. Thorax 1976;31:15-24.

13. Chahinian AP, Pajak TF, Holland JF, Norton L, Ambinder RM, Mandel EM. Diffuse malignant mesothelioma. Prospective evaluation of 69 patients. Ann Intern Med 1982;96:746-55.

14. Sugarbaker DJ, Flores RM, Jaklitsch MT, Richards WG, Strauss GM, Corson JM, et al. Resection margins, extrapleural nodal status, and cell type determine postoperative long-term survival in trimodality therapy of malignant pleural mesothelioma: results in 183 patients. J Thorac Cardiovasc Surg 1999; 117:54-65.

15. Flores RM, Akhurst T, Gonen M, Larson SM, Rusch VW. Positron emission tomography defines metastatic disease but not locoregional disease in patients with malignant pleural mesothelioma. J Thorac Cardiovasc Surg 2003;126:11-6.

16. Flores RM, Akhurst T, Gonen M, Zakowski M, Dycoco J, Larson SM, et al. Positron emission tomography predicts survival in malignant pleural mesothelioma. J Thorac Cardiovasc Surg 2006;132:763-8.

17. Hellstrom I, Raycraft J, Kanan S, Sardesai NY, Verch T, Yang $\mathrm{Y}$, et al. Mesothelin variant 1 is released from tumor cells as a diagnostic marker. Cancer Epidemiol Biomarkers Prev 2006; 15:1014-20.

18. Robinson BW, Creaney J, Lake R, Nowak A, Musk AW, de Klerk N, et al. Mesothelin-family proteins and diagnosis of mesothelioma. Lancet 2003;362:1612-6.

19. Zervos MD, Bizekis C, Pass HI. Malignant mesothelioma 2008. Curr Opin Pulm Med 2008;14:303-9.

20. Kojima T, Oh-eda M, Hattori K, Taniguchi Y, Tamura M, Ochi $\mathrm{N}$, et al. Molecular cloning and expression of megakaryocyte potentiating factor cDNA. J Biol Chem 1995;270:21984-90.

21. Yamaguchi N, Hattori K, Oh-eda M, Kojima T, Imai N, Ochi N. A novel cytokine exhibiting megakaryocyte potentiating activity from a human pancreatic tumor cell line HPC-Y5. J Biol Chem 1994;269:805-8.

22. Chang K, Pastan I. Molecular cloning of mesothelin, a differentiation antigen present on mesothelium, mesotheliomas, and ovarian cancers. Proc Natl Acad Sci USA 1996;93:136-40.

23. Scholler N, Fu N, Yang Y, Ye Z, Goodman GE, Hellström KE, et al. Soluble member(s) of the mesothelin/megakaryocyte potentiating factor family are detectable in sera from patients with ovarian carcinoma. Proc Natl Acad Sci USA 1999;96: 11531-36.

24. Muminova ZE, Strong TV, Shaw DR. Characterization of human mesothelin transcripts in ovarian and pancreatic cancer. BMC Cancer 2004;4:19.

25. Pass HI, Lott D, Lonardo F, Harbut M, Liu Z, Tang N, et al. Asbestos exposure, pleural mesothelioma, and serum osteopontin levels. N Engl J Med 2005;353:1564-73.

26. Ivanov SV, Ivanova AV, Goparaju CM, Chen Y, Beck A, Pass HI. Tumorigenic properties of alternative osteopontin isoforms in mesothelioma. Biochem Biophys Res Commun 2009;382: 514-8. Epub 2009 Mar 13.

27. Ge X, Yamamoto S, Tsutsumi S, Midorikawa Y, Ihara S, Wang $\mathrm{SM}$, et al. Interpreting expression profiles of cancers by genome-wide survey of breadth of expression in normal tissues. Genomics 2005;86:127-41.

28. Battifora HM. Tumors of the cardiovascular system. Atlas of tumor pathology, Vol. Washington, DC: Armed Forces Institute of Pathology, 2003.

29. Byrne MJ, Davidson JA, Musk AW, Dewar J, van Hazel G, Buck M, et al. Cisplatin and gemcitabine treatment for malignant mesothelioma: a phase II study. J Clin Oncol 1999;17: 25-30.

30. Flores RM, Krug LM, Rosenzweig KE, Venkatraman E, Vincent A, Heelan R, et al. Induction chemotherapy, extrapleural pneumonectomy, and postoperative high-dose radiotherapy for locally advanced malignant pleural mesothelioma: a phase II trial. J Thorac Oncol 2006;1:289-95.

31. Flores RM, Zakowski M, Venkatraman E, Krug L, Rosenzweig $\mathrm{K}$, Dycoco J, et al. Prognostic factors in the treatment of malignant pleural mesothelioma at a large tertiary referral center. J Thorac Oncol 2007;2:957-65.

32. van Meerbeeck JP, Gaafar R, Manegold C, Van Klaveren RJ, Van Marck EA, Vincent M, et al. Randomized phase III study 
of cisplatin with or without raltitrexed in patients with malignant pleural mesothelioma: an intergroup study of the European Organisation for Research and Treatment of Cancer Lung Cancer Group and the National Cancer Institute of Canada. J Clin Oncol 2005;23:6881-9.

33. Vogelzang NJ, Rusthoven JJ, Symanowski J, Denham C, Kaukel E, Ruffie P, et al. Phase III study of pemetrexed in combination with cisplatin versus cisplatin alone in patients with malignant pleural mesothelioma. J Clin Oncol 2003;21:263644.

34. Scherpereel A, Lee YC. Biomarkers for mesothelioma. Curr Opin Pulm Med 2007;13:339-443.

35. Beyer HL, Geschwindt RD, Glover CL, Tran L, Hellstrom I, Hellstrom KE, et al. MESOMARK: a potential test for malignant pleural mesothelioma. Clin Chem 2007;53:666-72. Epub 2007 Feb 8. 